\title{
Monetary Policy and the Uncovered Interest Rate Parity Puzzle
}

David K. Backus, Chris Telmer and Stanley E. Zin June 2008 


\section{UIP Puzzle}

- Standard regression:

\section{- UIP Puzzle}

- Carry Trade Payoffs

- Question

- Basic Idea

- Assumption 1

- Facts About UIP Puzzle

-...continued

Results

Interpretation

Last Thoughts

References, etc.

$$
s_{t+1}-s_{t}=\alpha+\beta\left(i_{t}-i_{t}^{*}\right)+\text { residuals }
$$

Estimates of $\beta$ are around -2 .

- Equivalent regression:

$$
s_{t+1}-f_{t}=\alpha+(\beta-1)\left(f_{t}-s_{t}\right)+\text { residuals }
$$

- LHS is payoff to "carry trade:" receive GBP, deliver USD.

- If $\beta \neq 1 \Longrightarrow$ carry trade payoffs are predictable. 


\section{Carry Trade Payoffs}

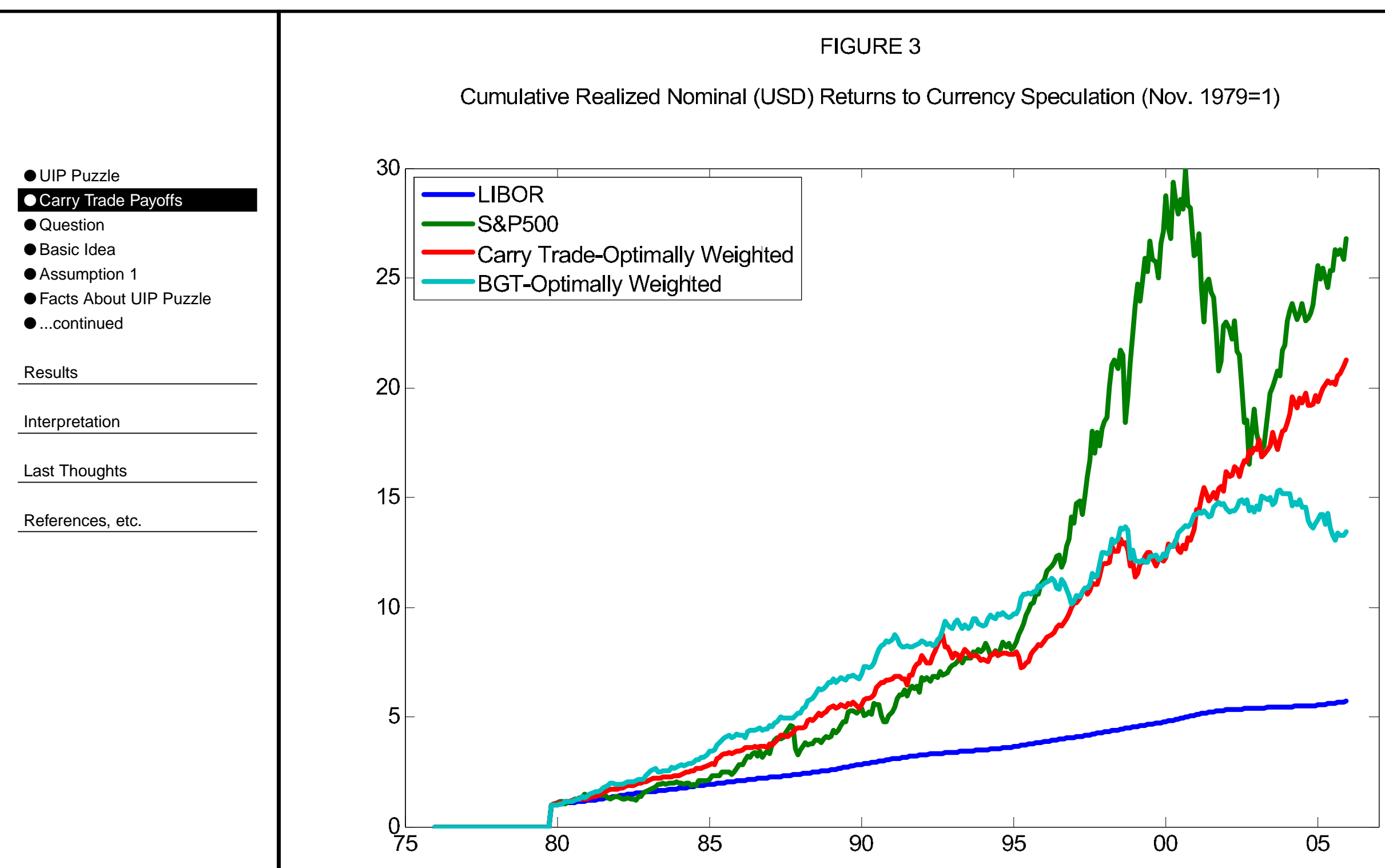

From "The Returns to Currency Speculation," by Burnside, Eichenbaum, Kleshchelski and Rebelo, August 2006. 


\section{Question}

Taylor rules:

UIP Puzzle

Carry Trade Payoffs

OQuestion

- Basic Idea

- Assumption 1

- Facts About UIP Puzzle

-...continued

Results

Interpretation

Last Thoughts

References, etc.

$$
\begin{aligned}
& i_{t}=\tau+\tau_{1} \pi_{t}+z_{t} \\
& i_{t}^{*}=\tau^{*}+\tau_{1}^{*} \pi_{t}^{*}+z_{t}^{*}
\end{aligned}
$$

Is the UIP puzzle a reflection of these sorts of interest rate rules?

- Builds on McCallum (1994)

- Also Gallmeyer, Hollifield, Palomino, and Zin (2007) 


\section{Basic Idea}

- Taylor rule and Euler equation:

- UIP Puzzle

- Carry Trade Payoffs

- Question

\section{- Basic Idea}

- Assumption 1

- Facts About UIP Puzzle

-...continued

Results

Interpretation

Last Thoughts

References, etc.

$$
\begin{aligned}
& i_{t}=\tau+\tau_{1} \pi_{t}+z_{t} \\
& i_{t}=-\log E_{t} n_{t+1} e^{\pi_{t+1}}
\end{aligned}
$$

- Imply difference equation for inflation:

$$
\pi_{t}=-\frac{1}{\tau_{1}}\left(\tau+z_{t}+\log E_{t} n_{t+1} e^{\pi_{t+1}}\right)
$$

- Exchange rate:

$$
\frac{S_{t+1}}{S_{t}}=\frac{n_{t+1}^{*} e^{\pi_{t+1}^{*}}}{n_{t+1} e^{\pi_{t+1}}}
$$




\section{Assumption 1}

- Constant real exchange rate:

$$
n_{t+1}=n_{t+1}^{*}=1 \quad \Longrightarrow \quad i_{t}=-\log E_{t} e^{-\pi_{t+1}}
$$

- Carry Trade Payoffs

- Question

- Basic Idea

Dassumplion 1 Model:

- Facts About UIP Puzzle

-...continued

$\underline{\text { Results }}$

Interpretation

Last Thoughts

References, etc.

$$
\begin{gathered}
i_{t}=\tau+\tau_{1} \pi_{t}+z_{t} \\
i_{t}^{*}=\tau^{*}+\tau_{1}^{*} \pi_{t}^{*}+z_{t}^{*} \\
\pi_{t}=-\frac{1}{\tau_{1}}\left(\tau+z_{t}+\log E_{t} e^{\pi_{t+1}}\right) \\
\pi_{t}^{*}=-\frac{1}{\tau_{1}^{*}}\left(\tau^{*}+z_{t}^{*}+\log E_{t} e^{\pi_{t+1}^{*}}\right) \\
\log \left(S_{t+1} / S_{t}\right)=\pi_{t+1}-\pi_{t+1}^{*}
\end{gathered}
$$




\section{Facts About UIP Puzzle}

1. Stochastic volatility not an option.

- Fama's decomposition:

$$
\begin{aligned}
i_{t}-i_{t}^{*} & =\left(f_{t}-E_{t} s_{t+1}\right)+\left(E_{t} s_{t+1}-s_{t}\right) \\
& \equiv p_{t}+q_{t}
\end{aligned}
$$

$p_{t}=0 \Longrightarrow$ UIP

- Backus, Foresi, and Telmer (2001), with lognormality:

$$
\begin{aligned}
p_{t} & =-\frac{1}{2}\left(\operatorname{Var}_{t}\left(m_{t+1}\right)-\operatorname{Var}_{t}\left(m_{t+1}^{*}\right)\right) \\
& =-\frac{1}{2}\left(\operatorname{Var}_{t}\left(\pi_{t+1}\right)-\operatorname{Var}_{t}\left(\pi_{t+1}^{*}\right)\right)
\end{aligned}
$$

- Difference equation, with lognormality:

$$
\pi_{t}=-\frac{1}{\tau_{1}}\left(\tau+z_{t}+E_{t} \pi_{t+1}-\frac{1}{2} \operatorname{Var}_{t}\left(\pi_{t+1}\right)\right)
$$




\section{...continued}

2. Restrictions on conditional mean and variance.

UlP Puzzle

- Carry Trade Payoffs

- Question

- Basic Idea

- Assumption 1

- Facts About UIP Puzzle

- ...continued

Results

Interpretation

Last Thoughts

References, etc.

- Fama, mapped into (lognormal) pricing kernel language:

$$
\begin{aligned}
i_{t}-i_{t}^{*} & =p_{t}+q_{t} \\
q_{t} & =-E_{t}\left(\log \pi_{t+1}-E_{t} \log \pi_{t+1}^{*}\right) \\
p_{t} & =-\frac{1}{2}\left(\operatorname{Var}_{t}\left(\pi_{t+1}\right)-\operatorname{Var}_{t}\left(\pi_{t+1}^{*}\right)\right)
\end{aligned}
$$

- Fama's necessary conditions for $\beta<0$ :

$$
\begin{aligned}
\operatorname{Cov}(p, q) & <0 \\
\operatorname{Var}(p) & >\operatorname{Var}(q)
\end{aligned}
$$




\section{Results}

- Result 1: Symmetry

- Result 2: Asymmetry

- Result 2: Interpretation

Interpretation

Last Thoughts

References, etc. 


\section{Result 1: Symmetry}

- UIP Puzzle

- Carry Trade Payoffs

- Question

- Basic Idea

- Assumption 1

- Facts About UIP Puzzle

-...continued

Results

O Result 1: Symmetry

- Result 2: Asymmetry

- Result 2: Interpretation

Interpretation

Last Thoughts

References, etc.

$$
\begin{aligned}
i_{t} & =\tau+\tau_{1} \pi_{t}+z_{t} \\
i_{t} & =-\log E_{t} e^{\pi_{t+1}} \\
z_{t} & =\varphi_{z} z_{t-1}+v_{t-1}^{1 / 2} \varepsilon_{t} \\
v_{t} & =\theta_{v}\left(1-\varphi_{v}\right)+\varphi_{v} v_{t-1}+\sigma_{v} w_{t}
\end{aligned}
$$

- Solution for inflation is

$$
\pi_{t}=a+a_{1} z_{t}+a_{2} v_{t}
$$

- Foreign equations are the same, with identical coefficients, but different shocks, $\varepsilon_{t}^{*}$ and $w_{t}^{*}$.

- If $\rho_{z}=0$,

$$
\beta=\frac{\varphi_{v}}{\tau_{1}}
$$




\section{Result 2: Asymmetry}

- Same symmetric equations as Result 1 , except ...

- UIP Puzzle

- Carry Trade Payoffs

- Question

- Basic Idea

- Assumption 1

- Facts About UIP Puzzle

-...continued

Results

- Result 1: Symmetry

OResult 2: Asymmetry

- Result 2: Interpretation

Interpretation

Last Thoughts

References, etc.

- Taylor rules are:

$$
\begin{aligned}
i_{t} & =\tau+\tau_{1} \pi_{t}+z_{t} \\
i_{t}^{*} & =\tau^{*}+\tau_{1}^{*} \pi_{t}^{*}+z_{t}^{*}+\tau_{3}^{*} \log \left(S_{t} / S_{t-1}\right)
\end{aligned}
$$

- If the domestic and foreign shocks are independent, then

$$
\beta<0 \quad \text { if } \quad \tau_{3}^{*}<-\tau_{1}^{*}
$$




\section{Result 2: Interpretation}

- UIP Puzzle

- Carry Trade Payoffs

- Question

- Basic Idea

- Assumption 1

- Facts About UIP Puzzle

-...continued

\section{Results}

- Result 1: Symmetry

- Result 2: Asymmetry

O Result 2: Interpretation

Interpretation

Last Thoughts

References, etc.

- If $\tau_{1}=\tau_{1}^{*}=1.1$, then, for example, $\tau_{3}^{*}=-1.2$

$$
i_{t}^{*}=\tau^{*}+\tau_{1}^{*} \pi_{t}^{*}+z_{t}^{*}+\tau_{3}^{*} \log \left(S_{t} / S_{t-1}\right)
$$

- Since $\log \left(S_{t} / S_{t-1}\right)=\pi_{t}-\pi_{t}^{*}$,

$$
i_{t}^{*}=\tau^{*}+\left(\tau_{1}^{*}-\tau_{3}^{*}\right) \pi_{t}^{*}+z_{t}^{*}+\tau_{3}^{*} \pi_{t}
$$

If $\tau_{1}=1.1$, then, for example, $\tau_{3}^{*}=-1.2$ and $\tau_{1}^{*}-\tau_{3}^{*}=2.3$ 


\section{Interpretation \\ - Carry Trade Payoffs \\ - Question \\ - Basic Idea \\ - Assumption 1 \\ - Facts About UIP Puzzle \\ -...continued \\ Results}

\section{Interpretation}

- Important Restriction

- Downward Bias

- Negative Correlation?

Last Thoughts

References, etc. 


\section{Important Restriction}

What does the Taylor rule do?

- Carry Trade Payoffs

- Question

- Basic Idea

- Assumption 1

- Facts About UIP Puzzle

-...continued

\section{Interpretation}

\section{O Important Restriction}

- Downward Bias

- Negative Correlation?

Last Thoughts

References, etc.

- Provides an endogenous link between the mean and variance of the pricing kernel. Consider exogenous inflation:

$$
\pi_{t+1}=\alpha+\delta v_{t}+\gamma v_{t}^{1 / 2} \varepsilon_{t+1}
$$

If $\delta-\gamma^{2} / 2<0$, then $\beta<0$.

- Here is what the Taylor rule implies:

$$
\pi_{t+1}=a+a_{2} \varphi_{v} v_{t}+a_{1} v_{t}^{1 / 2} \varepsilon_{t+1}+\text { stuff }
$$

For $\beta<0$, need $\varphi_{v}<0$. 


\section{Downward Bias}

- UIP Puzzle

- Carry Trade Payoffs

- Question

- Basic Idea

- Assumption

- Facts About UIP Puzzle

-...continued

Results

Interpretation

- Important Restriction

O Downward Bias

- Negative Correlation?

Last Thoughts

References, etc.

$$
\begin{aligned}
s_{t+1}-s_{t} & =\alpha+\beta\left(i_{t}-i_{t}^{*}\right)+\text { residuals } \\
i_{t} & =\tau+\tau_{1} \pi_{t}+z_{t} \\
\Longrightarrow \beta & =\frac{\varphi_{v}}{\tau_{1}}
\end{aligned}
$$

- If $\tau>1$ interest rates move more than inflation.

- But the problem is more dynamic that this: $\varphi_{v}$ matters:

$$
\pi_{t}=C-\frac{a_{1}^{2}}{2 \tau_{1}} E_{t}\left(v_{t}+v_{t+1}+v_{t+2}+\ldots\right)-\frac{1}{\tau_{1}} E_{t}\left(z_{t}+z_{t+1}+z_{t+2}+\ldots\right)
$$

- Mean moves less than variance because mean terms get discounted twice. 


\section{Negative Correlation?}

- UIP Puzzle

- Carry Trade Payoffs

- Question

- Basic Idea

- Assumption 1

- Facts About UIP Puzzle

-...continued

$\underline{\text { Results }}$

\section{Interpretation \\ - Important Restriction \\ - Downward Bias}

ONegative Correlation?

Last Thoughts

$\pi_{t}^{*}=C^{*}-E_{t}\left(\sum_{j=0}^{\infty} \frac{a_{1}^{* 2}}{2} \frac{v_{t+j}}{\phi^{j}}+\frac{a_{2}^{* 2}}{2} \frac{v_{t+j}^{*}}{\phi^{j}}+\frac{z_{t+j}^{*}}{\phi^{j}}+\tau_{3}^{*} \frac{\pi_{t+j}}{\phi^{j}}\right) / \phi$

References, etc.

where $\phi \equiv \tau_{1}^{*}-\tau_{3}^{*}$. 


\section{Last Thoughts \\ - Carry Trade Payoffs \\ - Question \\ - Basic Idea \\ - Assumption 1 \\ - Facts About UIP Puzzle \\ -...continued \\ Results}

Interpretation

\section{Last Thoughts}

- Alternative Specifications

- Last Thoughts

References, etc

References, etc.




\section{Alternative Specifications}

- Don't like the policy shocks? Consumption growth is $z_{t}$ :

- UIP Puzzle

- Carry Trade Payoffs

- Question

- Basic Idea

- Assumption 1

- Facts About UIP Puzzle

-...continued

$\underline{\text { Results }}$

Interpretation

Last Thoughts

- Alternative Specifications

- Last Thoughts

References, etc.

$$
\begin{aligned}
i_{t} & =-\log E_{t} n_{t+1}\left(z_{t+1}\right) e^{\pi_{t+1}} \\
i_{t} & =\tau+\tau_{1} \pi_{t}+z_{t} \\
\Longrightarrow \pi_{t} & =a+a_{1} z_{t}+a_{2} v_{t}
\end{aligned}
$$

- Or, output shocks:

$$
\begin{aligned}
\pi_{t} & =\alpha_{1} z_{t}+\alpha_{2} E_{t} \pi_{t+1} \\
i_{t} & =\tau+\tau_{1} \pi_{t}+z_{t} \\
i_{t} & =-\log E_{t} e^{-\pi_{t+1}} \\
\Longrightarrow \pi_{t} & =a+a_{1} z_{t}+a_{2} v_{t}
\end{aligned}
$$




\section{Last Thoughts}

- Carry Trade Payoffs

- Question

- Basic Idea

- Assumption 1

- Facts About UIP Puzzle

-...continued

Results

Interpretation

Last Thoughts

- Alternative Specifications

OLast Thoughts

References, etc.
- Different interest rate rules have different implications for currency risk premiums. Should this matter for optimal policy?

- Interest rate rules have implications for central bank balance sheets. Are central banks holding the losing side of the carry trade?

- Monetary union eliminates the carry trade. Are there welfare effects? 


\section{References, etc. \\ - Carry Trade Payoffs \\ - Question \\ - Basic Idea \\ - Assumption 1 \\ -...continued \\ $\underline{\text { Results }}$}

Interpretation

Last Thoughts

\section{References, etc.}

- References

- Notes

-...cont 


\section{References}

\section{References}

- UIP Puzzle

- Carry Trade Payoffs

- Question

- Basic Idea

- Assumption 1

- Facts About UIP Puzzle

-...continued

Results

Interpretation

Last Thoughts

References, etc.

OReferences

- Notes

-...cont
Backus, David K., Silverio Foresi, and Christopher I. Telmer, 2001, Affine term structure models and the forward premium anomaly, Journal of Finance 56, 279-304.

Gallmeyer, Michael F., Burton Hollifield, Francisco Palomino, and Stanley E. Zin, 2007, Arbitrage-free bond pricing with dynamic macroeconomic models, Working paper, Carnegie Mellon University.

McCallum, Bennett T., 1994, A reconsideration of the uncovered interest rate parity relationship, Journal of Monetary Economics 33, 105-132. 


\section{Notes}

- UIP Puzzle

- Carry Trade Payoffs

- Question

- Basic Idea

- Assumption 1

- Facts About UIP Puzzle

-...continued

Results

Interpretation

Last Thoughts

References, etc

- References

O Notes

-...cont

Structure

1. UIP puzzle is...(regression and its complement).

2. graph

3. Question: short-term interest rates, obviously, strongly influenced by policy (interest rate rules are commonplace). Given a process for $S_{t}$ that's consistent with these policies, is $\beta<0$ still a puzzle?

(a) Can/should the puzzle be recast from interest rate behavior to relative monetary policy behavior? Why are they doing this?

(b) Seems reasonable to me. What seems puzzling, to me, is that, for instance, Iceland was able to sustain a high interest policy for so long in the face of massive carry trade inflows.

(c) What's puzzling is that interest rate differentials remain persistently high in spite of lots of people trying to arb them.

4. Basic idea:

(a) Taylor rule

(b) Euler Eqn

(c) Non-linear diff equation gives solution for endogenous inflation

(d) Basic New-Keynesian idea: inflation (and therefore monetary policy) responds to the same underlying shocks as the real economy, consumption and the like.

(e) Exchange rate? Ratio of $m$ 's.

(f) Question made precise: is UIP manifest in these types of rules, which imply a particular path for future inflation and, therefore, exchange rates.

(g) McCallum

5. Assumption 1: real exchange rates are $=1$

6. Some facts about the UIP puzzle.

(a) Interest rate differential can be written as $p+q$. Mention Fama. BFT show that $p$ equals the difference in the cond. variances.

(b) Write the difference equation....show that what the macro guys do is set variance to zero. We can't....it's everything for us.

(c) What do you need? Mean and variance to move in the same direction...variance more. 
- UIP Puzzle

- Carry Trade Payoffs

- Question

- Basic Idea

- Assumption 1

- Facts About UIP Puzzle

-...continued

Results

Interpretation

Last Thoughts

References, etc.

- References

- Notes

O...cont

1. Result 1 .

2. Result 2.

3. Interpretations:

(a) What does Taylor do?

i. connects the mean and the variance endogenously....basic feature of the non-linear difference equation. For example, we can arbitrarily connect them (using the exogenous inflation example). The Taylor rule gives (i) an interpretation of why this connection is there (the non-linear difference equation, driven by the fact that the interest rate depends on the mean AND the variance), (ii) a restriction on the coefficients.

ii. Gives downward bias in natural way: (i) static intuition for $\tau_{1}$, using Stan's story of "the interest rates need to move MORE than the LHS, or, FX has just the mean, but interest rates have both the mean and the variance..... (ii) dynamic for $\varphi v$.

iii. Delivers Fama (2) but not (1)....for (1) we need some sort of asymmetry.... Taylor gives it in a natural way for the USD-centric world in which we live.

iv. Makes the entire future of shocks, inflation and so on matter. ie: for short rate, with exogenous inflation, all we care about is the cond. dist. of inflation at $t+1$. With Taylor, we care about future inflation, but since the central bank is committed to this interest rate rule, then we must care about next period's interest rate also. But next period's interest rate depends on inflation at $t+2 \ldots$ and so on. So, the static intuition can't be complete (ie, $\left.\tau_{1}>1\right)$.

4. 2nd last slide.....can cook it many different ways....same basic message.

5. Conclusions....can be used to evaluate different policies. Are central banks giving it up? Welfare effects of EMU? 